\title{
A Rare Complication of Lumbar Spinal Surgery: Pneumocephalus
}

\author{
Uğur Özdemir \\ Department of Neurosurgery, Ministry of Health, Beykoz State Hospital, Istanbul, Turkey
}

A 25-year-old male patient with severe thigh and right side pain was presented. In the lumbar magnetic resonance images, there was a contrasting spinal cord tumor image with $1 \mathrm{~cm}$ in diameter at the level of the L3 vertebra. The patient was operated and the tumor was totally removed. All the pain of the patient recovered. The patient's postoperative two days were very comfortable and the patient was early mobilized. On the third postoperative day, the patient complained of severe headache, nausea and vomiting. Immediate cranial computed tomography (CT) images was performed. Cerebral pneumocephalus was present in CT. The patient was treated with definite bed rest and plenty of fluid replacement. After three days, the patient's complaints were completely improved. This improvement was confirmed by performing a cerebral CT scan. In the formation of pneumocephalus, air is compressed into the intradural space during operation and this passes to the cerebral space. Definite bed rest, abundant fluid replacement and, in addition, highly inspired oxygen therapy are sufficient to correct the condition.

(Korean J Neurotrauma 2017;13(2):176-179)

KEY WORDS: Hydration · Oxygen therapy $\cdot$ Pneumocephalus $\cdot$ Spinal cord tumor.

\section{Introduction}

A case of pneumocephalus developed after spinal tumor surgery was investigated. Pneumocephalus is a pathologic gas collection in the epidural, subdural, subarachnoid, intraventricular, or intraparenchymal intracranial areas. The main causes of pneumocephalus are head trauma (74\%), intracranial neoplasms, infections, neurosurgical interventions, paranasal sinus surgeries and diagnostic interventions (such as pneumoencephalography or lumbar puncture). ${ }^{4}$ It was first described by Chiari ${ }^{6)}$ in 1884 . The causes, frequency and treatment of pneumocephalus were evaluated. In the formation of pneumocephalus, air is compressed into the intradural space during operation and this passes to the

Received: July 22, 2017 / Revised: September 1, 2017

Accepted: September 7, 2017

Address for correspondence: Uğur Özdemir

Department of Neurosurgery, Ministry of Health, Beykoz State Hospital, Saip Molla Street, Kisayol Sokak, No: 1, Istanbul, Turkey Tel: +90-216-322-2210, Fax: +90-216-413-7958

E-mail: drmelcy3@gmail.com

(c) This is an Open Access article distributed under the terms of Creative Attributions Non-Commercial License (http://creativecommons. org/licenses/by-nc/4.0/) which permits unrestricted noncommercial use, distribution, and reproduction in any medium, provided the original work is properly cited. cerebral space. Definite bed rest, abundant fluid replacement and, in addition, highly inspired oxygen therapy are sufficient to correct the condition. However, it is rarely necessary to apply surgical treatment.

\section{Case Report}

Our patient was a 25 -year-old man with severe thigh pain and right-sided back pain. On the patient's examination there was no significant finding except pain on the right lumbar region palpation. Lumbar magnetic resonance imaging (MRI) showed a spinal tumor image at the L3 vertebral level. The lesion was $1 \mathrm{~cm}$ in diameter. The boundaries of it could be clearly distinguished. At the same time, it was contrasting (Figure 1). The patient was operated after the preoperative preparations were completed. The tumor was intradural. His borders were fully distinguishable and rounded. So the lesion showed a benign image. Immediately after the operation, all the pain of the patient was improved. The patient was very comfortable within the postoperative two days. The patient was mobilized early in the first 24 hours. On the third postoperative day, severe headache, nausea and vomiting complaints developed in the patient. Immediate cranial computed tomogra- 
phy (CT) examination was performed in the patient. Cerebral pneumocephalus was present in CT (Figure 2). In our case, immobilization and abundant hydration provided healing. The treatment was successful and after three days all of the complaints of the patient had improved. At the same time, this improvement was confirmed by performing the cerebral CT examination (Figure 3).

\section{Discussion}

Pneumocephalus and gas in the spinal canal are rare neurosurgical complications. These complications are not only

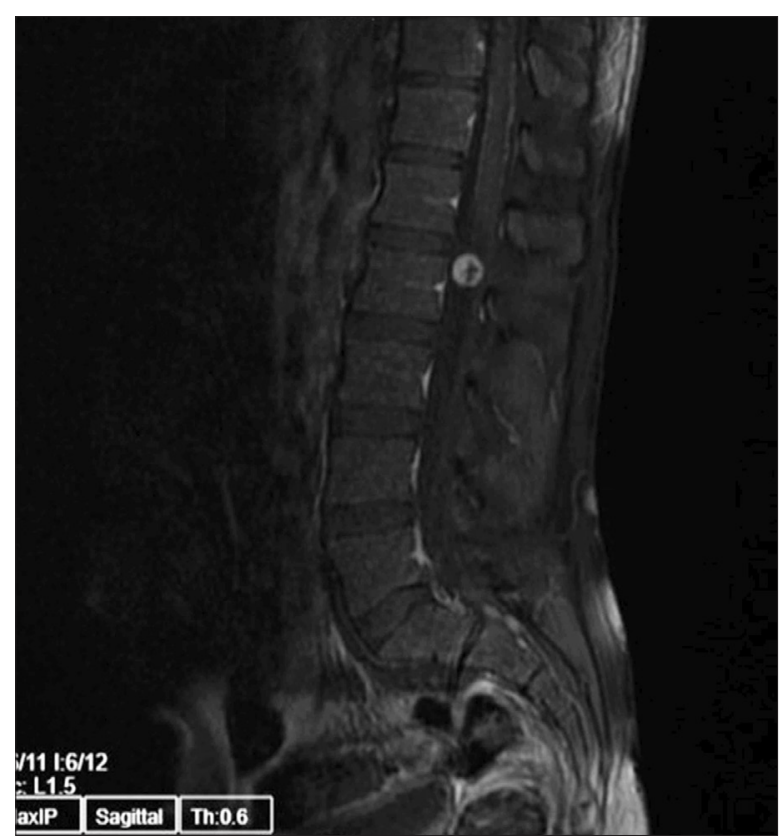

FIGURE 1. Intradural extramedullary enhancing tumor is noted at the 1 st lumbar level.

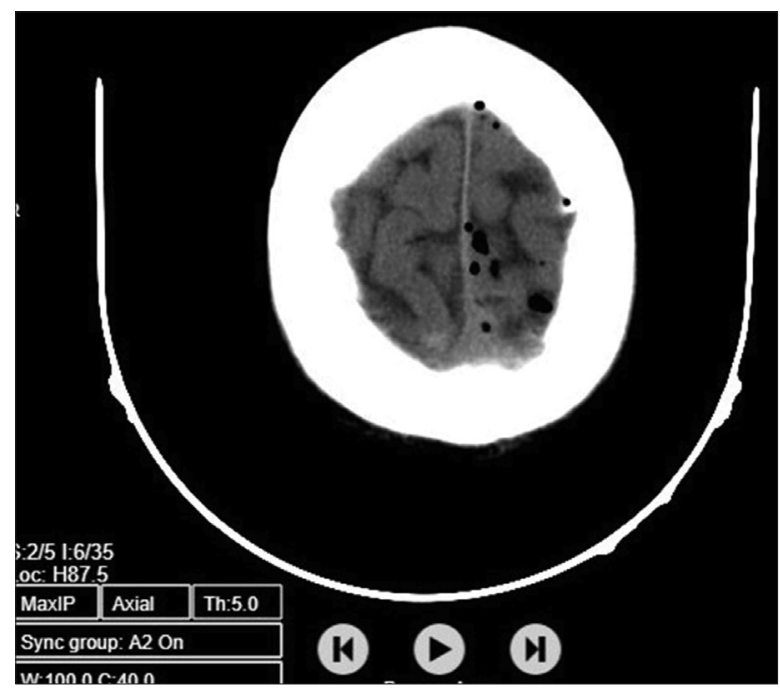

FIGURE 2. Brain computed tomography 3 days after lumbar surgery. Numerous air density is shown in the convexity area. due to direct surgery for spinal tumor removal. These are usually due to dura injury. ${ }^{1)}$ As in our case, after removal of the spinal intradural tumor, it is thought that air contact due to the openness of the surgical field and subsequent intradural compression of the air caused pneumocephalus. ${ }^{10)}$ The first complication that should be considered when an early confusion table develops after spinal surgery is pneumocephalus. Among the other factors that are effective in the confusion table, low hematocrit in advanced age is also remarkable. ${ }^{7}$ Among the case reports, a 60 -year-old patient with confusion, urinary incontinence and idiopathic rhinorrhea has also been shown to have pneumocephalus. ${ }^{16)}$ In neurosurgical operations, pneumocephalus occurs more frequently in operations performed in sitting position than in operations performed in prone and park bench positions. With the effect of gravity, the discharged cerebrospinal fluid (CSF) is displaced by air. ${ }^{18)}$ Interestingly, although there was no leakage of CSF during the operation, pneumocephalus and pneumorrhachis were seen. ${ }^{9)}$ In one study, it was presented a case of pneumocephalus without a clear complication after posterior spinal arthrodesis surgery. Conservative treatment was sufficient for the healing of this patient. In these cases, the presence of a dural defect was probably overlooked. Early diagnosis is necessary to prevent morbidity and mortality. It is necessary to have high suspicion for dural tear to accelerate treatment and improve pneumocephalus. ${ }^{2)}$ Another interesting case of pneumocephalus without dural injury during surgery was presented. CT cisternography and MRI did not reveal any anatomic defect that could lead to pneumocephalus. The authors of this case suggest that spontaneous pneumocephalus without dura injury may occur due to increased intraabdominal pressure

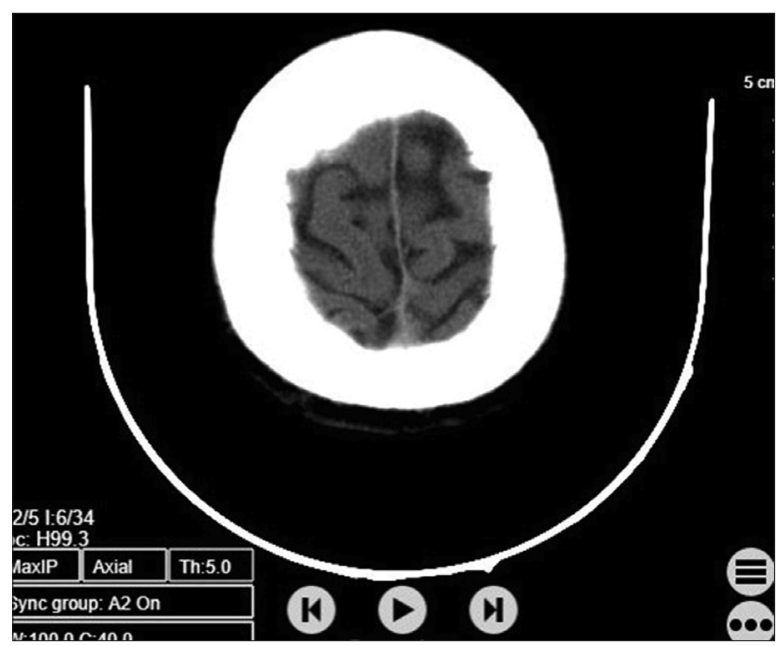

FIGURE 3. Brain computed tomography 3 days after conservative management. The previous noted air is completely disappeared. 
after spondylolisthesis surgery. For this reason, they reported that pneumocephalus could be prevented by carefully controlling the abdominal pressure in such cases. ${ }^{3)}$ It was also suggested that there was another disc surgery case that did not have an active dura defect detected during the operation. In this case, it was thought that the calcified disc fragment could cause dura ruptures in the axillary perineurium and this small tear site has been reported to function as a one-way valve system after disc removal, leading to pneumocephalus. In the same study, it was thought that when the vacuum suction device was placed on the fascia after spinal surgeries, it could be a predisposing factor in the development of pneumocephalus. ${ }^{11)}$ Apart from these surgical cases, pneumocephalus was observed in a patient who developed symptoms mimicking stroke after lomber epidural steroid injection. Pneumocephalus is a well-known complication of spinal and epidural anesthesia, but it is very rare after lumbar epidural steroid injection. ${ }^{8)}$ Continuous headache has developed in a patient who has undergone recurrently lumbar puncture for normal pressure hydrocephalus. It was observed that this was also due to pneumocephalus. ${ }^{12)}$ A study examining the lumbar puncture headaches was performed. In this study, it was found that the use of special puncture needles with thin tips was more effective in preventing pneumocephalus complication. ${ }^{13)}$ Apart from the mentioned cases, one of the interesting reasons explained in the development of pneumocephalus was the development of fistula between recurrent gastrointestinal tumor and sacral nerve root. This fistula helped the gastrointestinal gas to pass into the intracranial area and thus caused the pneumocephalus. ${ }^{17)}$ Pneumocephalus should be considered as a primary cause for severe headache and confusion situations associated with surgery or small epidural procedures. Surgery is often not necessary to treat pneumocephalus. Strict bed rest for a few days, highly inspired oxygen and infusion of excess fluid provide for the treatment of pneumocephalus. ${ }^{5)}$ Conservative treatment was discussed in more detail in some studies. Conservative treatments include avoiding valsalva maneuver, ie coughing and sneezing, raising the head of the bed by $30^{\circ}$ (Semi-Fowler's position), and administering antipyretics, painkillers, and osmotic diuretics. ') In a study of the healing effect of hyperbaric oxygen administration in the treatment of pneumocephalus, it was found that nitrogen absorption was facilitated in treated patients with hyperbaric oxygen compared to patients administering normal oxygen. ${ }^{15)}$ When clinical signs such as intracranial hypertension and unconsciousness begin to threaten life, surgical options, ie urgent decompression, should be considered to relieve the pressure on the brain parenchyma in the treatment of pneumocephalus. ${ }^{19)}$ In addition, burr hole opening, needle aspiration and dural defect closure are other surgical treatment options. ${ }^{14)}$

\section{Conclusion}

Pneumocephalus and gas in the spinal canal which are rare neurosurgical complications have been tried to be evaluated in this case report. This is usually caused by air escape to the intradural space after the dura injury. Pneumocephalus should be considered first when sudden confusion and headache develop after spinal surgery. When this situation is encountered, conservative treatment should be applied without fear. So surgery is often not necessary to treat pneumocephalus. Definite bed rest, highly inspired oxygen and excess fluid infusion are sufficient for the treatment of pneumocephalus. However, it should not be forgotten that surgical options should be taken into account when necessary.

- The author has no financial conflicts of interest.

\section{REFERENCES}

1) Akyüz O, Gökpınar D, Aydin E, Aydin S, Duymuş M, Çığşar G, et al. Pneumocephalus and pneumorrhachis after spinal surgery. Pol J Radiol 81:34-35, 2016

2) Andarcia-Bañuelos C, Cortés-García P, Herrera-Pérez MU, Deniz-Rodríguez B. Pneumocephalus: An unusual complication of lumbar arthrodesis. A clinical case and literature review. Rev Esp Cir Ortop Traumatol 59:222-226, 2015

3) Ayberk G, Yaman ME, Ozveren MF. Symptomatic spontaneous pneumocephalus after spinal fusion for spondylolisthesis. J Clin Neurosci 17:934-936, 2010

4) Baba M, Tarar O, Syed A. A rare case of spontaneous pneumocephalus associated with nontraumatic cerebrospinal fluid leak. Case Rep Neurol Med 2016:1828461, 2016

5) Becker WJ. Pneumocephalus as a cause for headache. Can J Neurol Sci 29:278-281, 2002

6) Chiari H. A case of acummulation of air in the ventricles of human brain. Z Heilkd 5:383-390, 1884

7) Dhamija B, Saxena A. Pneumocephalus - a possible cause of postspinal surgery confusion. J R Soc Med 104:81-83, 2011

8) Guarino AH, Wright NM. Pneumocephalus after a lumbar epidural steroid injection. Pain Physician 8:239-241, 2005

9) Karavelioglu E, Eser O, Haktanir A. Pneumocephalus and pneumorrhachis after spinal surgery: case report and review of the literature. Neurol Med Chir (Tokyo) 54:405-407, 2014

10) Kim JS, Choi KC, Jung B, Lee SH. Symptomatic pneumocephalus after spinal intradural tumor surgery. J Korean Neurotraumatol Soc 4:101-104, 2008

11) Kizilay Z, Yilmaz A, Ismailoglu O. Symptomatic pneumocephalus after lumbar disc surgery: a case report. Open Access Maced J Med Sci 3:143-145, 2015

12) Kozikowski GP, Cohen SP. Lumbar puncture associated with pneumocephalus: report of a case. Anesth Analg 98:524-526, 2004

13) Lambert DH, Hurley RJ, Hertwig L, Datta S. Role of needle gauge and tip configuration in the production of lumbar puncture headache. Reg Anesth 22:66-72, 1997 
14) Paiva-Neto MA, Tella Jr OI. Supra-orbital keyhole removal of anterior fossa and parasellar meningiomas. Arq Neuropsiquiatr 68 : 418-423, 2010

15) Paiva WS, de Andrade AF, Figueiredo EG, Amorim RL, Prudente M, Teixeira MJ. Effects of hyperbaric oxygenation therapy on symptomatic pneumocephalus. Ther Clin Risk Manag 10:769. 773,2014

16) Roberts GA, Foy PM, Bolger C. Idiopathic spontaneous cerebrospinal fluid rhinorrhoea and pneumocephalus: case report and literature review. Br J Neurosurg 10:513-517, 1996
17) Torres A, Holoye PY, Camacho LH. Spontaneous pneumocephalus associated with recurrent colorectal carcinoma. J Clin Oncol 26:5483-5484, 2008

18) Toung TJ, McPherson RW, Ahn H, Donham RT, Alano J, Long D. Pneumocephalus: effects of patient position on the incidence and location of aerocele after posterior fossa and upper cervical cord surgery. Anesth Analg 65:65-70, 1986

19) Venkatesh SK, Bhargava V. Clinics in diagnostic imaging (119). Post-traumatic intracerebral pneumatocele. Singapore Med J 48: 1055-1059, 2007 